\title{
Professional Self-Help in Alcoholism
}

\author{
GAReth Lloyd, General Practitioner, 2 Saxfield Drive, Baguley Hall, Manchester
}

The North West Doctors and Dentists Group is part of the wider British Doctors Group. In Britain Doctors' groups began when the London Group was formed in 1973. Since then new groups have been established in Birmingham, Bristol, Durham, Glasgow, Manchester, Northampton, Petersfield and Portadown.

Membership is restricted to doctors and dentists and meetings are private and confidential, but on occasion, nonalcoholic colleagues who have a special interest in the problem are invited to meetings. The singular objective is to help colleagues obtain and sustain sobriety.

Doctors' groups are not in competition with any other treatment agency, including hospital facilities and Alcoholics Anonymous. Rather do we see ourselves as a means of obtaining such treatment for those who desire it.

The North West Group began in a small way in April 1980 when two dentists and a doctor perceived a need. During the first three years a further 62 members have joined. Growth has been steady and is illustrated in Fig. 1.

From the outset, accurate records were maintained about referral source, professional status, date of joining the group, sex and address and all were updated as necessary. By the third anniversary of the Group in April 1983 a limited analysis was possible. Less complete information was available about marital state and family relationships, despite an active associated Family Group.

During March 1983 special enquiry was made to establish the sobriety status of each member, though no attempt was made to establish the severity of alcoholism. These measurements are undoubtedly crude and elementary. Nevertheless they provide a useful profile of the group and suggest both the need and the opportunity for more purposeful and objective assessment over a number of years. Such assessment is planned and all suggestions will be gratefully received.

Of the 65 members who joined the group between April 1980 and April 1983, 54 were doctors (48 male, 6 female) and 11 were dentists ( 8 male, 3 female). During these three years five members, all doctors, died. Three of these died of alcoholism-a male junior hospital doctor (suicide), a male general practitioner (inhalation of vomit) and a retired female surgeon (liver failure). Both who died of other causes were male - one had 20 years of continued sobriety and the other four.

Among the 49 surviving doctors, there are 31 general practitioners ( 27 male, 4 female), 8 junior hospital doctors ( 7 male, 1 female), 7 male consultants (3 psychiatrists, 1 neurologist, 2 pathologists and 1 radiologist), 1 RAMC officer and 2 men who have retired. Of the 11 surviving dentists, 7 are male general dental practitioners and 4 are

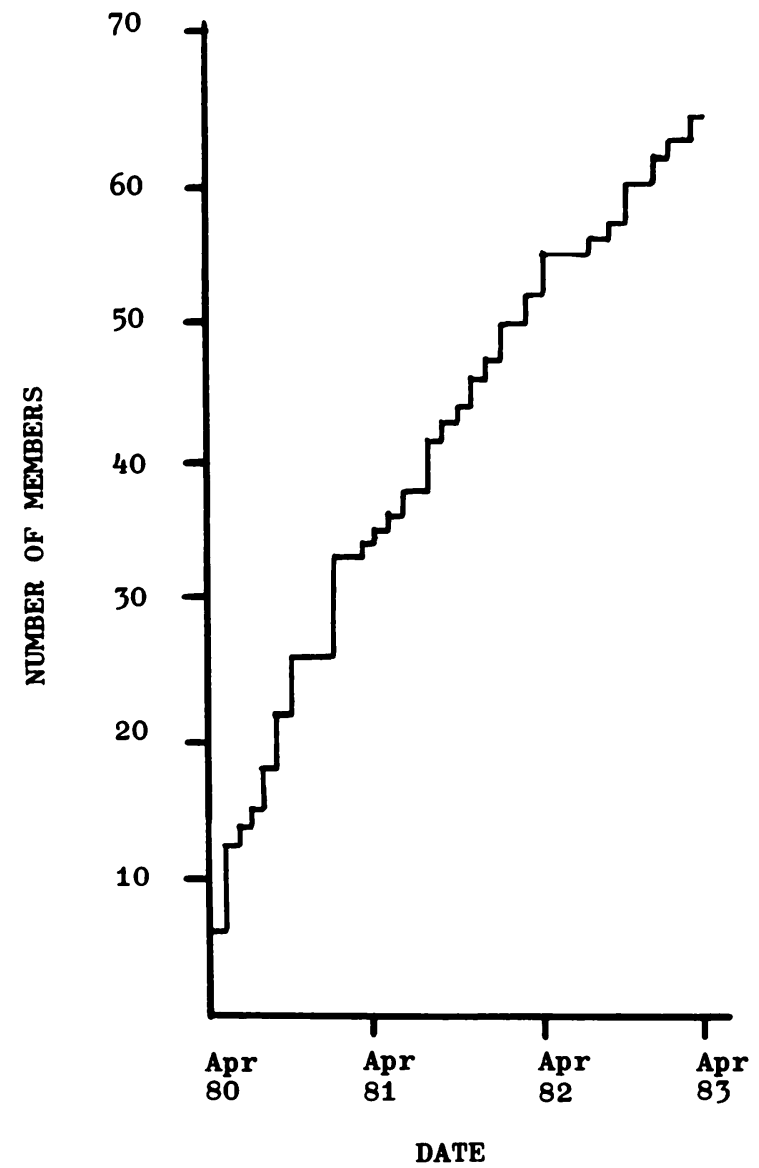

Fig. 1.-Growth of the North West Group.

community dental officers ( 3 female, 1 male).

While these numbers suggest a greater prevalence among general practitioners, it is not possible to make any real comparison because the relative populations of hospital doctors and general practitioners is not known, and no attempt has been made to estimate the relative proportions who might be attracted to group involvement.

Five members are unmarried. Forty are married and living with their spouse and 10 are separated or divorced. The marital state of two members is not known. Among the married, 31 spouses have made a contact with the Family Group, while nine have shown disinterest.

The growth of the North West Doctors and Dentists Group may in part be attributed to sympathetic therapists- 
in particular, Dr. B. D. Hore of Manchester and Dr. J. S. Madden of Chester, have encouraged their doctor and dentist patients to seek our help. Twenty-nine have reached us in this way. A further 20 have joined the Group in response to direct contact with existing members. The remaining 16 have been recommended by Councils on Alcoholism, family members and non-alcoholic colleagues. The importance to us of supportive specialists in the field of alcoholism cannot be too strongly emphasized.

Sobriety is notoriously difficult to determine with accuracy. There is, however, among a group of alcoholic doctors a real sense of identity with sobriety. An alcoholic who conceals a return to drinking from family and therapist is less likely to do so among fellow alcoholics.

In the March 1983 assessment of the state of sobriety of the Group, two measurements were made. Firstly, the number who had remained sober since joining the Group was estimated. Members were only considered to have sustained sobriety if their claim was supported by the evidence of at least two other persons, one of whom being a member of the Group. Contact at the time was suspended by emigration, etc. for four members. Of the remaining 56, 40 were considered to be sober since joining the Group, the mean duration of sobriety since April 1980 being 24 months, with a range of one to 36 months.

Secondly, the number of members sober for the six months prior to April 1983 was assessed. The same criteria of credibility were used and 40 out of 56 were sober. A further 5 were sober by their own unsupported evidence, and 11 were believed not to be sober during this six-month period.

There is a great deal of encouragement in these figures, though it has to be recognized that a truly objective assessor was not involved and the severity of alcoholism is not known.

There does seem to be evidence that the sympathetic identification, purposeful support and professional security which Doctors and Dentists Groups offer to colleagues is a valuable contribution to the overall management of the problem.

Much of the discussion at group meetings is concerned with the relationship between personal alcoholism and the practice of medicine or dentistry, a discussion which members find very difficult to have in other environments, including the psychiatrist's consulting room.

If you can help us please do so. We can see no valid reason why any practising professional should not at least come to know us. Of the 65 who have joined the North West Group, only one has requested that the notice of monthly meetings be discontinued. Even the alcoholic who continues drinking is reminded each month that somebody cares. We can be reached through the Medical Council on Alcoholism, 3 Grosvenor Crescent, London SW IX 7EE (01 234 4182).

\section{Awards and Honorary Fellowships}

The Royal Society of Medicine has awarded the 1983 Baron Dr ver Heyden de Lancy Law Prize to Professor Robert Bluglass. The prize is awarded annually to the Fellow adjudged to have made the most outstanding contribution to the advancement of the links between law and medicine.

Professor Sir Martin Roth and Dr John Horder have been elected Honorary Fellows of the Royal Society of Medicine.

\section{Training Posts in Mental Handicap-A Warning}

There appear to be a number of training posts, both SHO and Registrar, in mental handicap hospitals which are not connected up to any general training scheme. This has been discussed at the Court of Electors and by the Mental Handicap Section. They agree that in future all training posts in mental handicap hospitals must be part of a training scheme, so that they will generally be occupied by a particular trainee for not more than six months. In future, posts which are not integrated will not be given educational approval and should thus become available for redistribution.

I now read the advertisement section of the $B M J$ and
Lancet with renewed interest. (Some of them still advertise posts as suitable for the (defunct) DPM.) Some of my 'worried, Belgrave Square' letters turn out to be without foundation, and you then have the pleasure of letting me know that I have got hold of the wrong end of the stick.

J. L. T. BIRLEY Dean

\section{Monitoring the Mental Health Act}

The Public Policy Committee Working Party on the Mental Health Act has been asked to monitor the working of the Act and to note any problems or difficulties that arise. It would be glad to receive comments which may be sent to Professor Robert Bluglass, Chairman, PPC Working Party on the Mental Health Act, Royal College of Psychiatrists, 17 Belgrave Square, London SW IX 8PG.

\section{Dependence/Addiction Group: 1983-84}

The membership of the Dependence/Addiction Group for 1983-84 is as follows:

Chairman: Dr Thomas Bewley; Secretary: Dr I. Akhter; Executive Committee: Drs I. G. Christie, B. Hore, J. S. Madden, J. Morgan, K. J. B. Rix, J. Strang and A. P. Thorley. 